(NT-proBNP) protein was higher in patients with than in those without $\mathrm{AF}(6.23 \pm 0.62$ vs $4.72 \pm 0.33, \mathrm{p}=0.012$, $\mathrm{n}=176)$. We also performed an exploratory analysis only in patients without signs of coronary artery disease on CTCA $(\mathrm{AF}=27, \quad \mathrm{SR}=80) . \quad$ In this subgroup, NT-proBNP $(6.478 \pm 0.8442$ vs $4.554 \pm 0.4122, \mathrm{p}=0.023 *)$, BNP $\left(1.111 \pm 0.083\right.$ vs $\left.0.9713 \pm 0.029, \mathrm{p}=0.0175^{*}\right)$, Stem Cell Factor (SCF, $162.8 \pm 7.860$ vs $140.4 \pm 5.127 \mathrm{p}=$ $\left.0.0097^{* *}\right)$ and VEGF-D $(47.44 \pm 2.708$ vs $41.38 \pm 1.694 \mathrm{p}$ $\left.=0.0389^{*}\right)$ were higher in the 27 patients with AF.

Conclusion While NT-proBNP is mostly known as a marker for heart failure, NT-proBNP appears as a potential blood marker for $\mathrm{AF}$ in patients without history of stroke, hypertension, diabetes or heart failure. Further validation of these initial, hypothesis-generating results seems warranted.

\section{THE RELATIONSHIP BETWEEN CAROTID ARTERY INTIMAL-MEDIAL THICKNESS AND LEFT VENTRICULAR FUNCTION BY SPECKLE TRACKING ECHOCARDIOGRAPHY IN PATIENTS WITH CORONARY ARTERY DISEASE}

Hanan Radwan, Tamer Mostafa*, Abdelhakem Seleem, Ekhlas Hussein. Faculty of Medicine Zagazig University Hospital; *Presenting Author

\subsection{6/heartjnl-2016-309890.218}

Background and aim of the work Since cardiovascular diseases are associated with high mortality and generally undiagnosed before the onset of clinical findings, there is a need for a reliable tool for early diagnosis. Carotid intima-media thickness (CIMT) is a non-invasive marker of coronary artery disease (CAD) and is widely used in practice as an inexpensive, reliable method. Left ventricular (LV) function can be accurately assessed by $2 \mathrm{D}$ speckle-tracking strain echocardiography (2DSTE). In our study, we aimed to investigate the relationship of CIMT and LV function assessed by 2D-STE in patients with stable (CAD) and the ability of 2D-STE and CIMT to predict significant CAD.

Methods Cross sectional study included 40 patients with history suspected stable angina pectoris, normal LV ejection fraction. All patients were examined by 2D-STE, carotid ultraound, and coronary angiography (CA). 2D-STE was performed in the 3 apical projections. Peak regional longitudinal systolic strain was measured in 17 myocardial segments and averaged to provide global longitudinal peak systolic strain (GLS). LVGLS results were compared with CA findings in a receiver operating curve (ROC) to determine the cut-off for normal and abnormal strain values. The calculated optimal strain value was compared to mean CIMT measurements. The patients were divided into two groups according to the result of the CA: group 1 (29 patients) with significant coronary lesion $>70 \%$, and group 2 (11 patients) having at least one lesion more than $50 \%$ within the main branches of the coronary arteries.

Results GLS was significantly lower in patients with CAD+ (group 1) compared to patients without CAD- (group 2) $[-11.86 \pm 2.89 \%$ versus $-18.65 \pm 0.79 \%] \mathrm{P}<0.001$. ROC curve between GLS and CA showed cut-off value for LVGLS was less than $-15.6 \%$ for prediction of significant CAD with AUC $=0878 ; 95 \%$ CI $0.78-0.96$ p 0.00 . The diagnostic performance of GLS for detecting severity of CAD was [sensitivity $93.1 \%$, specificity $81.8 \%$ and accuracy $90 \%$ ]. The mean
CIMT was $1.49 \pm 0.35 \mathrm{~mm}$ in group 1 , vs $0.75 \pm 0.3 \mathrm{~mm}$ in group $(2)(p=0.000)$. ROC curve between mean CIMT and CA showed cutoff value for mean CIMT was $>1.1 \mathrm{~mm}$ for prediction of significant CAD with $\mathrm{AUC}=0.871 \quad(95 \% \mathrm{CI}$ $0.79-0.97, \mathrm{p}$ 0.00. There was a significant, nearly linear correlation between IMT and GLS and advancing CAD (p, 0.00), as there was incremental significant increase in CIMT and decrease of GLS with increasing number of coronary vessels involved. Further analyses showed that GLS was highly significant negatively correlated with mean CIMT.

Conclusion GLS assessed by 2DSTE at rest was predictor of significant CAD; So 2DSE seems capable of identifying highrisk patients. Increased carotid IMT values were associated with decreased LV function assessed by 2D strain measurements and the presence and severity of CAD. So these findings support the use of carotid IMT measurements as marker of subclinical LV dysfunction and to predict risk and severity of coronary heart disease.

\section{HIGHLY SELECTIVE TROPONIN T (HSTNT) AND HEART- TYPE FATTY ACID-BINDING PROTEIN (H-FABP) AS MARKERS OF TYPE 4A MYOCARDIAL INFARCTION AND ADVERSE EVENTS IN ELECTIVE PERCUTANEOUS CORONARY INTERVENTION (PCI)}

Michael Connolly*, James Shand, Michelle Kinnin, lan Menown, David Mc Eneaney. Craigavon Area Hospital; *Presenting Author

\subsection{6/heartjnl-2016-309890.219}

Introduction Heart-type Fatty Acid-Binding Protein (H-FABP) may be useful for early diagnosis of ACS1,2 and has been associated with increased cardiovascular events. Type 4a procedural myocardial infarction (MI) may occur after percutaneous coronary intervention (PCI).3 Little is known about the use of early biomarkers as predictors of cardiovascular events following elective PCI.

Methods We prospectively evaluated highly sensitive troponin $\mathrm{T}$ (hsTnT), H-FABP, troponin I (TnI), creatine kinase MB type (CKMB), myoglobin, glycogen phosphorylase BB (GPBB) and carbonic anhydrase III (CAIII) at $0,4,6$ and $24 \mathrm{~h}$ following elective PCI. Baseline demographic and cardiac risk factors were recorded. The primary endpoint was type $4 \mathrm{a} \mathrm{MI}$, diagnosed as a rise of $>5 \times 99^{\text {th }}$ upper reference limit (URL) of $14 \mathrm{ng} / \mathrm{L}$ (i.e. rise of $>70 \mathrm{ng} / \mathrm{L}$ ) at $6 \mathrm{~h}$ if hsTnT was normal at baseline or $>20 \%$ from 0 to $6 \mathrm{hrs}$ if hsTnT was $>14 \mathrm{ng} / \mathrm{L}$ at baseline. 3 Patients were followed up at 1 year to assess for

\section{Median hsTnT release in type $4 \mathrm{a} \mathrm{MI}$ and no type 4a MI}

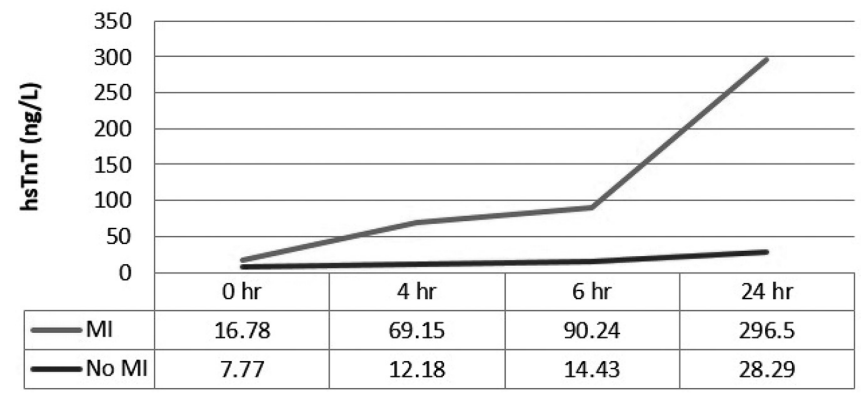

Abstract 219 Figure 1 hsTnT release between type 4a MI ( $=37$ ) and no type $4 \mathrm{a} \mathrm{MI}(\mathrm{n}=172)$ 


\section{Median H-FABP release in type 4a MI and no type $4 \mathrm{a} \mathrm{MI}$}

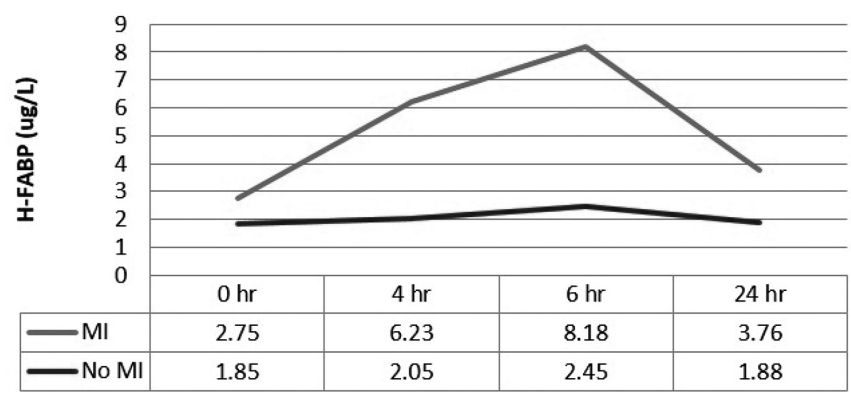

Abstract 219 Figure 2 H-FABP release between type $4 a \mathrm{MI}(\mathrm{n}=37)$ and no type $4 \mathrm{a} \mathrm{Ml}(\mathrm{n}=172)$

major adverse clinical events (MACE); MI, target vessel revascularisation, heart failure, stroke and death.

Results We enrolled 241 patients of whom 32 were excluded due to withdrawal of consent or PCI being cancelled after angiography. A cohort of 209 patients was included in analysis, of whom $144(68.9 \%)$ were male, mean age was 68.8 years, $28(13.4 \%)$ were smokers, $31(14.8 \%)$ were diabetic, 199 (95.2\%) had hypercholesterolaemia and 138 (66.0\%) had hypertension. Type 4a MI was observed in 37 (17.7\%) patients. Comparing those with and without type $4 \mathrm{a}$ MI, there was no statistical difference in risk factors $(p>0.05)$ except for age, $(\mathrm{p}=0.015)$. Median troponin at $6 \mathrm{~h}$ was $90.24 \mathrm{ng} / \mathrm{L}$ (95\% CI 76.56 â€” 186.41) versus $14.43 \mathrm{ng} / \mathrm{L}$ (95\% CI $16.37 \hat{\mathrm{a}} € ” 21.26)$ in the type $4 \mathrm{a} /$ non type $4 \mathrm{a}$ groups respectively, $p=<0.001$, Figure 1 . Median H-FABP at $4 \mathrm{~h}$ was most predictive of type $4 \mathrm{a}$ MI (followed by CKMB and myoglobin) with levels of $6.23 \mathrm{mg} / \mathrm{L}$ (95\% CI 4.38-18.96), versus $2.05 \mathrm{mg} / \mathrm{L}$ (95\% CI 2.23-2.74), $\mathrm{p}=<0.001$, AUC 0.91, Table 1, Figure 2. Results for TnI, CKMB, myoglobin, GBPP and CAIII are shown in Table 1. Multivariate logistic regression (stepwise elimination) showed H-FABP to be most predictive of type $4 \mathrm{a}$ MI, $\mathrm{p}<0.001$. Sensitivity of $4 \mathrm{~h} \mathrm{H}$-FABP (>6.32 mg/L) for type 4a MI was $51.5 \%$, specificity $96.1 \%$, positive predictive value (PPV) $73.9 \%$, negative predictive value (NPV) 90.3\%, odds ratio (OR) 26.39, relative risk (RR) 7.62. MACE was noted in $6(2.9 \%)$ patients (three MI, two death and one stroke), 3 of which had type $4 \mathrm{a}$ MI at index PCI, $p=0.036$. Table 2 compares median change in H-FABP and hsTnT from 0 â€" $6 \mathrm{~h}$ in patients who developed MACE at 1 year with CAIII performing best, $\mathrm{p}=0.02$.

Conclusions/implications Median $4 \mathrm{~h}$ H-FABP was most predictive of a $6 \mathrm{~h}$ hsTnT rise as a consequence of type $4 \mathrm{a} \mathrm{MI}$

Abstract 219 Table 1 Summary of biomarker results at $4 \mathrm{~h}$

\begin{tabular}{|c|c|c|c|c|c|c|}
\hline \multirow[b]{2}{*}{$4 \mathrm{hr}$ biomarker } & \multicolumn{2}{|c|}{ Type 4a MI } & \multicolumn{2}{|c|}{ No type 4a MI } & \multirow[b]{2}{*}{ AUC } & \multirow[b]{2}{*}{$\begin{array}{c}p \\
\text { value }\end{array}$} \\
\hline & Median & IQR & Median & IQR & & \\
\hline $\mathrm{H}-\mathrm{FABP}(\mu \mathrm{g} / \mathrm{L})$ & 23 & 6.22 & 2.05 & 1.45 & 0.91 & $<0.001$ \\
\hline & .18 & 0.07 & $<0.18$ & 0.01 & 0.62 & 0.004 \\
\hline & 3.54 & 3.37 & 2. & 1.25 & 0.75 & $<0.001$ \\
\hline Myo & 72.75 & 55.68 & 35.82 & 38.91 & 0.72 & $<0.001$ \\
\hline GP & & 3.50 & & 2.48 & 0.50 & \\
\hline CAll & 28.76 & 23.67 & 25.25 & 26.41 & 0.60 & 0.16 \\
\hline
\end{tabular}

H-FABP: heart-type fatty acid-binding protein; hsTnT: highly sensitive troponin $\mathrm{T}$; Tnl: troponin I; CKMP: creatine kinase MB; GPBB: glycogen phosphorylase; CAll: carbonic anhydrase III; IQR: interquartile range; AUC: area under curve
Abstract 219 Table 2 Summary of biomarker change from 0-6 $h$ in 1 year MACE and non-MACE patients

\begin{tabular}{|c|c|c|c|c|c|c|}
\hline \multirow{2}{*}{ Biomarker } & \multicolumn{2}{|c|}{ MACE } & \multicolumn{2}{|c|}{ No MACE } & \multirow[b]{2}{*}{ AUC } & \multirow[b]{2}{*}{$\begin{array}{c}\mathrm{p} \\
\text { value }\end{array}$} \\
\hline & $\begin{array}{l}\text { Median } \\
\text { change }\end{array}$ & IQR & $\begin{array}{l}\text { Median } \\
\text { change }\end{array}$ & IQR & & \\
\hline hsTnT (ng/L) & 38.32 & 135.61 & 7.07 & 23.49 & 0.94 & 0.06 \\
\hline $\mathrm{H}-\mathrm{FABP}(\mu \mathrm{g} / \mathrm{L})$ & 3.73 & 21.36 & 0.56 & 2.45 & 0.91 & 0.04 \\
\hline $\mathrm{Tnl}(\mu \mathrm{g} / \mathrm{L})$ & 0.47 & 0.01 & 0.09 & 0.22 & 0.97 & 0.11 \\
\hline CK-MB $(\mu \mathrm{g} / \mathrm{L})$ & 0.45 & 4.01 & 0.18 & 1.14 & 0.89 & 0.29 \\
\hline Myoglobin (ng/n & 15.47 & 185.49 & 2.80 & 36.55 & 0.94 & 0.07 \\
\hline GPBB (pg/L) & -0.86 & 8.08 & 1.75 & 5.13 & 0.71 & 0.31 \\
\hline CAIII $(\mu \mathrm{g} / \mathrm{L})$ & 24.13 & 18.23 & 1.08 & 20.91 & 0.91 & 0.02 \\
\hline
\end{tabular}

H-FABP: heart-type fatty acid-binding protein; hsTnT: highly sensitive troponin $\mathrm{T}$; $\mathrm{Tnl}$ : troponin I; CKMP: creatine kinase MB; GPBB: glycogen phosphorylase; CAlll: carbonic anhydrase III; IQR: interquartile range; AUC: area under curve

in elective PCI, followed by CKMB and myoglobin. H-FABP and CAIII were independently predictive of MACE at 1 year and MACE was associated with type $4 \mathrm{a}$ MI at index PCI.

\section{Young Investigators Prize 2016}

\section{A $\quad$ THE CORONARY ARTERY DISEASE ASSOCIATED GENE HHIPL1 PROMOTES ATHEROSCLEROSIS}

\footnotetext{
1,2Dimitra Aravani*, 1,2Elisavet Karamanavi, 1,2Sarah L Andrews, 1,2Nilesh J Samani,

1,2Emma J Stringer, '1,2Thomas R Webb. 'Department of Cardiovascular Sciences, University of Leicester, Cardiovascular Research Centre; ${ }^{2}$ NIHR Leicester Cardiovascular Biomedical Research Unit, Glenfield Hospital, Leicester, LE3 9QP, UK; *Presenting Author
}

\subsection{6/heartjnl-2016-309890.220}

Genome-wide association studies have identified chromosome $14 \mathrm{q} 32$ as a locus for coronary artery disease in humans. The disease associated variants fall in a gene called Hedgehog interacting protein-like 1 (HHIPL1), which encodes an uncharacterised sequence homolog of a Hedgehog protein antagonist. Here, we present our investigation of HHIPL1 function and its role in atherosclerosis.

Epitope tagged HHIPL1 protein is present in the media of HHIPLI transfected cells and immunoprecipitates with GFP tagged Sonic Hedgehog $(\mathrm{SHH})$ protein, demonstrating that HHIPL1 is a secreted interactor of SHH. We measured HHIPL1 gene expression in different cardiovascular cell types and found that it is primarily expressed in aortic smooth muscle cells (AoSMCs). We performed siRNA knock-down of HHIPL1 in AoSMCs and observed a reduction of $32 \%(+/-$ $11 \%)$ in proliferation $(\mathrm{p}=0.002$ at $72 \mathrm{~h}$ ) and a reduction of $27 \%(+/-4 \%)$ in migration $(\mathrm{p}=0.02$ at $12 \mathrm{~h})$. We went on to examine the role of Hhipl1 in atherosclerosis in vivo. In atherosclerotic mouse aortas Hhipl1 expression increased with disease progression ( $\sim 2$-fold increase at 6 weeks vs 32 weeks of age, $\mathrm{p}=0.001)$. We crossed Hbipl1 $1^{-/-}$mice onto Apoe $e^{-/}$and $\mathrm{Ldll}^{-/-}$atherosclerosis prone backgrounds. Hhipl1 ${ }^{-/-}$mice displayed a reduction of $57 \%(+/-28 \%)$ in lesion area compared with controls on an $\mathrm{Ldlr}^{-/}$background (en face aorta, $\mathrm{n}=10$ Hhipl1 ${ }^{+/+}$; Ldlr $r^{-/}$vs $\mathrm{n}=19$ Hhipl1 $^{-/-} ;$Ldlr $^{-/}$, t-test $\mathrm{p}=$ $0.00007)$ and $49 \%(+/-28 \%)$ reduction on an Apoe $e^{-/}$background (en face aorta, $\mathrm{n}=9$ Hhipl $^{+/+} ;$Apoe $^{-/-}$vs $\mathrm{n}=17$ Hhipl1 $^{-/-}$; Apoe $e^{-/-}$, t-test $\left.\mathrm{p}=0.0004\right)$.

Our data represent the first experimental investigation of HHIPL1. We find that HHIPL1 is a proatherogenic protein that regulates smooth muscle cell proliferation and migration, 